\title{
Crenças e atitudes linguísticas: uma análise da avaliação de professores da rede pública de ensino Linguistic beliefs and attitudes:
} an analysis of public school teachers' evaluation

\author{
Wéllem Aparecida de Freitas Semczuk \\ Universidade Estadual de Londrina (UEL), Londrina/PR - Brasil
}

\begin{abstract}
Resumo
Pensando no ensino por meio da diversidade linguística, o intuito deste trabalho era verificar o posicionamento dos profissionais que atuam na docência de língua portuguesa em relação à abordagem da variação linguística em sala. A coleta de dados foi realizada para uma pesquisa de mestrado, através de um questionário destinado aos professores que realizavam o curso do PDE (Plano de Desenvolvimento da Educação). Os resultados mostraram que os informantes apresentaram avaliações subjetivas e, entre as concepções linguísticas vigentes, destaca-se a concepção de que a língua se define por um conjunto de regras consubstanciadas nas gramáticas normativas, as quais prescrevem as normas do "falar e escrever corretamente", sendo todas as formas desviantes desse padrão consideradas como "erro".
\end{abstract}

Palavras-chave: Variação linguística, Atitudes linguísticas, Ensino de língua materna, Preservação da face

\begin{abstract}
From thinking of teaching through linguistic diversity, the main scope of this essay is to verify the position of professionals who act in the Portuguese Language teaching in relation to the linguistic variety approach in classroom. The data have been part of a masters research, collected through a questionnaire directed to teachers who were taking the PDE (Education Development Plan) course. The results showed that the informers have presented subjective evaluations and, among the current linguistic conceptions, they have highlighted a concept that the language is defined by normative grammars rules, which prescribe the rules of "talking and writing correctly", considering as "mistake" everything deviating from this pattern. Keywords: Linguistic variety, Linguistic attitude, Teaching of native language, Figure preservation
\end{abstract}

\section{Introdução}

A língua portuguesa brasileira é resultado do contato com várias outras línguas: o português europeu, as línguas indígenas do tronco tupi, a língua dos vários grupos africanos trazidos à época da colonização e a língua dos imigrantes. 
Graças a essa miscigenação, percebe-se a heterogeneidade da língua encontrada nos âmbitos social e cultural.

O presente trabalho tem por objetivo geral verificar o posicionamento dos profissionais que atuam hoje como docentes de língua portuguesa, com relação à abordagem da variação linguística em sala, e avaliar seus conhecimentos a respeito de sociolinguística, tendo como foco os aspectos relacionados à variação e à atitude linguística. Para tanto, nossos objetivos específicos são: (i) avaliar os conhecimentos dos professores a respeito da variação linguística; (ii) investigar se os informantes acreditam na importância da variação linguística e se abordam esse conteúdo em sala.

Pautando-nos nesses objetivos, temos como tema central a abordagem da variação linguística em sala de aula e a visão de alguns docentes sobre tal fenômeno.

Esta pesquisa é de caráter, predominantemente, qualitativo e, para tanto, selecionamos como corpus para a análise as respostas ao questionário realizado com professores da rede pública de ensino.

\section{Normas e variação linguística}

Os falantes atuam em diferentes espaços, cumprindo, portanto, diferentes papéis que apresentam características sociais involuntárias (nível sociocultural, sexo, idade) e escolhas voluntárias (seleção de um registro adequado à situação). Os papéis sociais são assim definidos por Bortoni-Ricardo (2004, p. 23) "os papéis sociais são um conjunto de obrigações e de direitos definidos por normas socioculturais. Os papéis sociais são construídos no próprio processo de interação humana".

Por estarmos envolvidos em uma situação social e por compreendermos a língua, enquanto algo indissociável da sociedade, assumimos a posição de Faraco (2008), quando salienta que a variação está intimamente ligada à língua, não havendo, portanto, distinção entre elas, falar de uma é falar da outra.

Coseriu, no início da década de 1950, altera a perspectiva saussureana dicotômica (langue/parole, sistema/fala) e a modifica para uma perspectiva tricotômica, acrescentando a norma (sistema/norma/fala). Sua tricotomia vai do mais concreto (fala, uso individual da norma) ao mais abstrato (língua, sistema 
funcional), passando por um grau intermediário: a norma (uso coletivo da língua). Em outras palavras, há realizações consagradas pelo uso e que, portanto, são normais em determinadas circunstâncias linguísticas, previstas pelo sistema funcional. A norma seria assim um primeiro grau de abstração da fala. Considerando-se a língua (o sistema) um conjunto de possibilidades abstratas, a norma seria então um conjunto de realizações concretas e de caráter coletivo da língua. Dessa maneira, o autor seguiu a visão estruturalista da língua, tendo por inspiração o modelo saussureano. Faraco (2008) conceitua norma como:

Cada um dos diferentes modos sociais de realizar os grandes esquemas de relações do sistema. Nesse sentido, cada norma se organiza como um certo arranjo de possibilidades admitidas pelo sistema. Cada um desses arranjos se desenha a partir do uso corrente, habitual de determinado grupo de falantes socialmente definido. (FARACO, 2008, p. 34)

Assim, a norma é dotada de organização, não importando qual sua abordagem, como bem enfatiza Faraco (2008), possui uma organização estrutural, consequentemente, é errôneo afirmar que possuem falantes que, analfabetos ou que empregam a variedade popular, falam sem utilizar uma gramática, porque é impossível falar sem gramática. Tendo isso por base, a noção de "erro" em uma língua se torna incoerente, visto que há uma base organizacional, contudo, essa base pode estar amparada em outra norma.

Faraco (2008, p. 36) afirma ainda ser papel do linguísta "desenvolver instrumentos descritivos adequados para dar conta das diferenças de organização estrutural entre as muitas normas de uma língua”.

\section{Crenças e atitudes linguísticas}

O estudo das atitudes linguísticas está relacionado à avaliação linguística, isto é, aos julgamentos que os falantes fazem tanto com relação a sua língua quanto ao dialeto utilizado por outro interlocutor. A variação linguística adicionada aos valores sociais, ou seja, às avaliações a respeito de determinadas línguas, conduzem para uma classificação como melhor ou pior, mais bonita ou mais feia, o que pode tanto incluir quanto excluir algumas variantes linguísticas.

Lambert e Lambert (1966, p. 77) definem a atitude como "uma maneira organizada e coerente de pensar, sentir e reagir em relação a pessoas, grupos, questões sociais ou, mais genericamente, a qualquer acontecimento ocorrido em 
nosso meio circundante". Para os autores, as crenças e atitudes humanas se fundamentam em quatro atividades do homem - pensar, sentir, comportar-se e interagir -, que correspondem aos quatro fundamentos psicológicos das crenças e atitudes - cognitivos, emocionais, comportamentais e sociais.

López Morales (1993) identifica, na atitude, apenas o componente conativo, separando o conceito de crença do de atitudes e os situando em níveis diferentes:

Las creencias sí pueden estar integradas por una supuesta cognición y por un integrante afectivo. Aunque no todas las creencias producen actitudes (piénsese, por ejemplo, en las etimologías populares), en su mayoría conllevan una toma de posición: si se cree que el fenómeno $X$ es rural, es decir, lleva signos de rusticidad, inelegancia, etc. se suele producir una actitud negativa hacia él, se suele rechazar. Que tal rechazo afecta a la actuación lingüística del hablante es un hecho, sobre todo cuando produce estilos cuidadosos en los que participa muy activamente su conciencia lingüística. (LÓPEZ MORALES, 1993, p. 235) ${ }^{1}$

Aguilera (2008) afirma que as atitudes de valorização ou mesmo de rejeição a determinadas variedades da língua em uso são condicionadas por grupos sociais de mais prestígio, ou seja, os que definem o que tem prestígio e status. Alkmim (2007) afirma que, em todas as comunidades de fala, haverá uma hierarquia, pois,

$\mathrm{Na}$ realidade objetiva da vida social, há sempre uma ordenação valorativa das variedades linguísticas em uso, que reflete a hierarquia dos grupos sociais. Isto é, em todas as comunidades existem variedades que são consideradas superiores e outras inferiores. (ALKMIM, 2007, p.39)

Nesse sentido, cumpre esclarecer que a presente pesquisa está direcionada para o estudo de crenças, isto é, analisamos a posição em que os professores colocam os objetos (língua, linguagem, variação e aprendizagem linguística) dentro da dimensão avaliativa, posição essa que, em última instância, leva à atitude deles em relação a esses objetos.

\section{Ensino de língua materna}

Temos, na maioria das escolas, o ensino exclusivo da gramática idealizada, que não condiz com as diversas normas do português brasileiro, pois ainda impera a visão purista da língua, o que dificulta a abordagem da diversidade linguística.

\footnotetext{
${ }^{1}$ As crenças podem estar integradas por uma suposta cognição e por um integrante afetivo. Ainda que nem todas as crenças produzam atitudes (imagine, por exemplo, nas etimologias populares), em sua maioria, implicam numa tomada de decisão: se se acredita que o fenômeno $X$ é rural, isto é, leva signos de rusticidade, deselegância etc., costuma-se produzir uma atitude negativa em relação a ele, costuma-se rejeitá-lo. Que tal rejeição afeta à atuação linguística do falante é um fato, sobretudo quando produz estilos cuidadosos, nos quais sua consciência linguística participa ativamente (Tradução nossa).
}

Revista Educação Online Rio de Janeiro, n. 23, set-dez 2016, p. 84-96 
Afinal, o indivíduo, quando chega à escola, já tem domínio da língua falada, logo, é importante que se trabalhe com a diversidade, conforme aponta Mattos e Silva (2004):

Qualquer indivíduo normal que entre na escola para ser alfabetizado em sua língua materna já é senhor de sua língua, na modalidade oral própria a sua comunidade de fala. Admitindo esse princípio, qualquer trabalho de ensino da língua materna se constitui em um processo de enriquecimento do potencial linguístico do falante nativo, não se perdendo de vista a multiplicidade de comunidades de fala que compõe o universo de qualquer língua natural, multiplicidade que variará, a depender das características de cada uma, enquanto língua histórica, isto é, língua inserida tanto sincrônica quanto diacronicamente no contexto histórico em que se constitui e em que se constituiu. (MATTOS E SILVA, 2004, p. 27)

O ensino de língua sempre passou por discussões. Os alunos, muitas vezes, não conseguem relacionar o que aprendem nas aulas de língua portuguesa ao que vivenciam, já que os conteúdos seguem uma metodologia distante de sua realidade, de sua comunidade de fala, ou seja, ainda há a busca da norma literária, conforme aponta Mattos e Silva (2003):

A busca dessa norma literária, fundada nos clássicos gregos, não é mais do que a busca da manutenção de uma tradição que interessava aos alexandrinos preservar, de uma cultura erudita, representada nas "grandes obras" de autores ilustres da civilização grega clássica do passado, cujos exemplos deveriam ser seguidos. A norma se explicitava nas regras e nos exemplos que funcionariam e funcionaram como prática a ser imitada. Recurso presente até hoje em múltiplas gramáticas pedagógicas em nossa tradição cultural. (MATTOS E SILVA, 2003, p. 15)

Com a acolhida democrática, chegou até a instituição escolar um novo grupo de alunos, passando a existir um conflito entre a linguagem ensinada na escola, que é a norma das classes privilegiadas, e a linguagem das camadas populares. Assim, é preciso que o docente de língua portuguesa saiba qual é objetivo do ensino frente a essa nova realidade, conforme apontam os Parâmetros Curriculares Nacionais:

O objetivo do ensino e, portanto, de aprendizagem, é o conhecimento linguístico e discursivo com o qual o sujeito opera ao participar das práticas sociais mediadas pela linguagem. Organizar situações de aprendizado, nessa perspectiva, supõe: planejar situações de interação nas quais esses conhecimentos sejam construídos e/ou tematizados; organizar atividades que procurem recriar na sala de aula situações enunciativas de outros espaços que não o escolar, considerando-se sua especificidade e a inevitável transposição didática que o conteúdo sofrerá; saber que a escola é um espaço de interação social onde práticas sociais de linguagem acontecem e se circunstanciam, assumindo características bastante específicas em função de sua finalidade: o ensino. (BRASIL, 1998, p. 22)

Revista Educação Online Rio de Janeiro, n. 23, set-dez 2016, p. 84-96 
Verificamos que, nos Parâmetros Curriculares, encontra-se a orientação para abordar em sala a diversidade da língua, isto é, não deve ser considerado em sala apenas o ensino da norma padrão. Faraco (2008, p. 177) completa que, por causa dessas orientações, o tema da variação linguística acabou sendo incorporado pelo discurso pedagógico, porém, "não conseguimos ainda construir uma pedagogia adequada a essa área. Talvez porque não tenhamos ainda, como sociedade, discutido suficientemente, no espaço público, nossa heterogênea realidade linguística, nem a violência simbólica que a atravessa".

\section{Preservação da face}

Nas diversas formas de comunicação, principalmente face-a-face, é comum que o falante se coloque em uma posição vulnerável, pois precisará, muitas vezes, arriscar, publicamente, sua autoimagem (face), externando suas opiniões, crenças, conhecimentos etc.

Primeiramente, é importante colocar que o conceito de face foi estabelecido por Goffman na década 1970, a partir do quadro geral de interação face-a-face. Dessa maneira, por correr o risco de exibir o que deseja que fique "escondido", acabam adotando procedimentos que lhes permitam controlar a construção dessa autoimagem. Na pesquisa que realizamos, há questões que poderiam evidenciar o desconhecimento dos atuais profissionais da área de letras, com relação aos estudos sociolinguísticos. Os informantes, por receio ou para não serem alvos de críticas, optaram por mecanismos linguísticos que não evidenciassem o que não desejavam mostrar, conforme aponta Galembeck (2005):

Nos textos conversacionais, o emprego dos procedimentos em questão se torna particularmente relevante, pois os interlocutores sabem que a manifestação direta de opiniões pode torná-los vulneráveis a críticas e opiniões contrárias. É importante, por isso, promover o apagamento das marcas de enunciação (ROSA, 1992, p. 40), o que é obtido com o uso de certos recursos gramaticais utilizados para a expressão da impessoalidade (é possível que, parece que, é provável) e da indeterminação do sujeito (dizem, falam, diz-se), e, também, com o emprego dos marcadores de rejeição (não sei, se não me engano). (GALEMBECK, 2005, p.175176)

O falante, muitas vezes, opta por utilizar recursos cuja propriedade é assinalar a atitude de compromisso com o pesquisador diante dos conceitos por ele assumidos. Esses recursos são os marcadores de opinião (acho, creio, vejo, noto, na minha opinião, no que me diz respeito), a alusão a terceiros (polifonia), os 
"hedges" (assim, quer dizer, digamos, vamos dizer, talvez, quem sabe, sei lá, não sei) e as paráfrases.

A partir dos estudos apresentados nesta seção, buscamos, a seguir, analisar o corpus constituído para a presente pesquisa.

\section{Análise do questionário aplicado aos professores}

$\mathrm{Na}$ questão 1, pretendíamos saber o tempo de experiência dos professores da rede pública de ensino, conforme mostra o gráfico.

Gráfico 1: Tempo de atuação dos docentes na rede pública de ensino

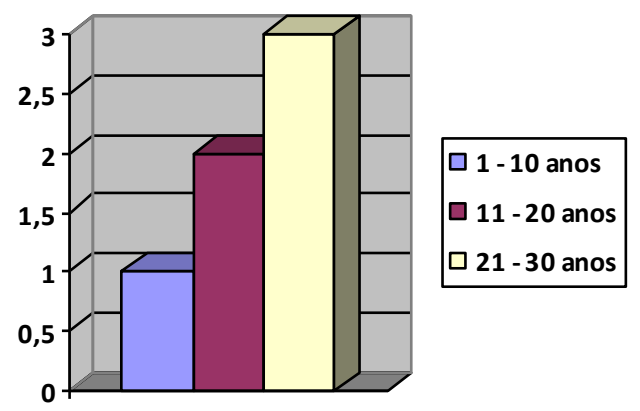

$\mathrm{Na}$ pergunta seguinte, os professores precisavam fazer uma avaliação de sua atuação em sala de aula; logo, analisamos que os docentes se sentem mais satisfeitos com a sua prática, em detrimento da parte teórica, fato que se justifica pelo tempo de serviço, afinal, os professores, participantes da pesquisa estão há mais de dez anos ministrando aulas.

A pergunta 3 apresentava uma afirmação: "sabemos que o ensino de língua portuguesa passou por transformações e que devemos considerar o que o aluno traz de conhecimento sobre a língua, afinal já fala português"; após essa afirmação, interrogamos se realmente é necessário abordar a língua, considerando seu uso no meio social; em caso afirmativo, por qual motivo. As respostas foram todas afirmativas, isto é, os seis professores concordaram que devemos considerar a norma que o aluno traz de casa e especificaram, conforme mostra a tabela 1, os motivos de tal afirmação. 
Tabela 1: Abordagem da língua pelos docentes

\section{Informantes Informante P1}

Informante P2
Informante P3

Informante P4

Informante P5

Informante P6

\section{Motivos}

Pois a língua é viva e passa por transformações através do tempo, e é imprescindível que 0 aluno a conheça pra se comunicar adequadamente nas diversas situações a que venha a passar.

Devemos mostrar e propor o correto a ele.

Porque pertencemos ao um país superdesenvolvido, onde só se fala uma língua, portanto, devemos considerá-la no meio social.

Pois a língua é viva e deve ser ensinada de forma que o aluno a use adequadamente nas diferentes situações de conversação, leitura e escrita.

Pois devemos considerar o que o aluno já sabe, preparar para ele ser um ser pensante na sociedade, para o seu dia a dia.

Porque o aluno precisa dominar a língua culta para usá-la nas situações que exigem seu uso e também saber que há situações informais (com a família em casa) em que a língua que ele já domina cumpre com a função de comunicar, interagir.

De acordo com as respostas, conseguimos depreender algumas atitudes linguísticas, como no caso do informante 2, que afirma ser necessário abordar a língua considerando seu uso no meio social, mas menciona que é imprescindível "propor o correto" ao aluno, quer dizer, o professor ainda julga o ensino da língua materna enquanto "certo" e "errado", "correto" e "incorreto", desconsiderando, por consequência, suas variedades, isto é, seu uso no meio social. Em vista disso, sua alegação de que é preciso considerar os conhecimentos que o aluno traz de casa é contestada e demonstra sua preocupação em preservar a face, diante do pesquisador.

Os outros informantes falaram da adequação da linguagem à situação comunicativa, o que vai ao encontro da proposta sociolinguística. Cremos que todos os informantes responderam de maneira positiva por causa do enunciado da questão, uma vez que, antes de questionarmos a respeito do ensino, trouxemos uma afirmação, o que acabou por direcionar as respostas dos professores.

A próxima questão, pergunta número 4, buscava identificar quais conteúdos os professores mais utilizam em sala de aula, visto que temos somente professores com experiência e que trabalham na rede pública de ensino. Desse modo, julgamos ser mais fácil para eles identificarem quais conteúdos são a base do ensino em língua portuguesa. Por isso, elencamos diversos conteúdos, e os informantes só deveriam assinalar quais julgavam/avaliavam mais importantes, podendo haver mais de uma alternativa. 
Gráfico 2: Conteúdos abordados em sala

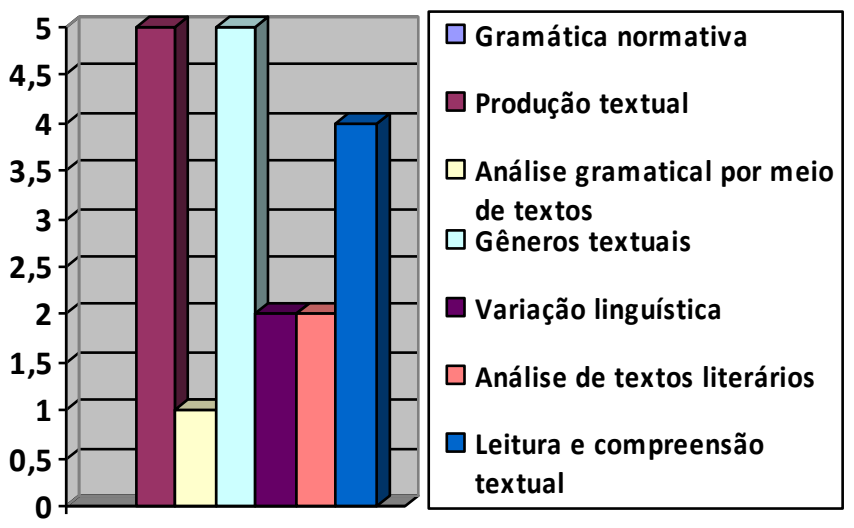

As respostas foram diversas e, mesmo constando o conteúdo de "variação linguística”, somente dois informantes julgaram necessário abordar a diversidade da língua, o que contradiz as respostas da questão 3, em que todos afirmaram ser importante trabalhar a língua considerando seu uso no meio social. A mudança nas respostas pode ter ocorrido, principalmente, porque, na questão anterior, houve um direcionamento na pergunta, para que os professores afirmassem a importância de considerar a língua em seu contexto sócio-histórico e, nesta questão, em que não havia o direcionamento, os professores ficaram mais à vontade e julgaram/avaliaram de acordo com suas práticas e crenças.

As respostas dos professores foram diversificadas dependendo do que constava na pergunta, porque, nas questões em que esperávamos uma afirmação por parte dos informantes em relação ao tema da variação linguística, havendo indícios dessa informação, os professores respondiam de maneira positiva, isto é, tinham por intuito preservar a face frente ao entrevistador, visto que, quando não havia tal informação, os professores ignoravam o tema e, por meio de atitudes, evidenciavam suas crenças.

Os conteúdos mais escolhidos se referem à produção textual e ao ensino dos gêneros textuais. A opção "gramática normativa" não foi escolhida por nenhum dos professores, o que nos causou dúvidas em decorrência da avaliação normativa feita na questão número 3 e que pode, mais uma vez, apontar para uma busca de preservação da face. 
Seguindo essa abordagem, questionamos, na questão 5 , se, ao longo da formação, os professores tiveram contato com questões relacionadas à sociolinguística, e metade dos informantes respondeu positivamente; um informante disse não, e os outros dois disseram ter visto, porém, muito pouco, conforme apresenta o gráfico 3 .

Gráfico 3: Conhecimento a respeito das pesquisas da sociolinguística

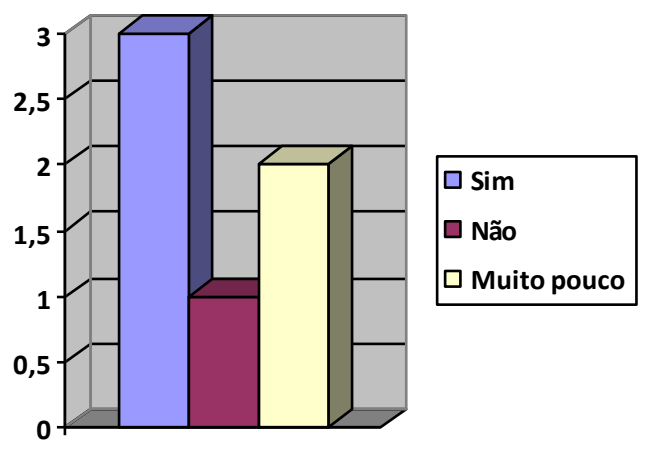

Ao analisarmos o gráfico 3, nossa hipótese fora confirmada, porque cremos que a maioria dos professores, principalmente os que estão há mais tempo em sala de aula e que fazem poucos cursos de formação continuada, desconhecem os estudos sociolinguísticos. Por esse motivo, ainda julgam a língua sob a dicotomia de "certo e errado", ou melhor, acreditam que o ensino de língua materna acontece pelo uso exclusivo da gramática normativa, considerando, nas diversas situações comunicativas, apenas se o termo utilizado está de acordo com os preceitos da gramática, sem levar em consideração a diversidade linguística.

Ainda, a respeito dos conteúdos, perguntamos quais acreditam ser mais importantes para abordar em sala de aula e por qual motivo. 
Tabela 2: Conteúdos mencionados pelos docentes como importante para o ensino de língua materna

Conteúdo
Leitura
Oralidade
Escrita
Gêneros textuais
Análise linguística
Interpretação de textos
Gramática

Conteúdo

Gramática

\author{
Informantes \\ P1, P2, P3, P4, P6 \\ P1, P2, P3, P6 \\ $\mathrm{P} 1, \mathrm{P} 2, \mathrm{P} 4, \mathrm{P} 6$
}

$\mathrm{P} 3, \mathrm{P} 4, \mathrm{P} 6$

$\mathrm{P} 2$,

$\mathrm{P} 4$,

P3
Número de vezes

05

04

04

03

01

01

01

As respostas foram, praticamente, as mesmas da questão 4, contudo, nesse caso, nenhum informante mencionou a variação linguística ou mesmo a diversidade da língua. Uma possibilidade de interpretação dos dados pode ser que os dois professores que optaram por esse conteúdo na alternativa anterior o fizeram, apenas porque estava como opção, isto é, a própria pergunta trazia esse assunto, sem, realmente, fazer seu uso em sala.

Os conteúdos mais elencados foram leitura, oralidade e escrita, juntamente com os gêneros textuais, visto que os informantes mencionaram, diversas vezes, que o ensino por meio dos gêneros possibilita e auxilia os três eixos em questão, oralidade, escrita e leitura. Apesar disso, somente um informante mencionou o conteúdo gramatical.

As questões anteriores procuravam verificar se os professores avaliam ser importante abordar a pluralidade linguística, todavia, não obtivemos muito sucesso nas respostas. Dessa maneira, a questão 7 trazia essa indagação, e a resposta, mais uma vez, fora afirmativa, como já esperávamos. Na tabela 3 , temos os motivos elencados por alguns professores. 
Tabela 3: Os motivos para o trabalho com a diversidade da língua em sala de aula elencados pelos professores

Informantes

Informante P1

Informante P4

Informante P6

\section{Motivos}

Pois precisamos valorizar e respeitar as variantes trazidas pelos nossos alunos.

Pois é através dessa diversidade de linguagens, que o aluno compreende a importância de aprimorar sua própria língua e conhecer línguas novas, para melhor se contextualizar neste nosso mundo globalizado.

O aluno precisa saber que não há uma única linguagem correta (culta), mas sim a linguagem adequada para cada situação.

As respostas marcaram que, realmente, é preciso abordar a variação linguística em sala, já que todos os professores a julgaram de forma positiva. No entanto, esperava-se encontrar esse posicionamento, esperado nas questões anteriores, mas isso não ocorreu. Temos, mais uma vez, a presença da conservação da face diante do pesquisador, porque uma pesquisa que tem como foco o ensino, ou mesmo sua prática docente, deixa o entrevistado em uma situação vulnerável, já que precisará externar sua opinião, crenças, avaliações de forma pública, que, posteriormente, serão analisadas. Isso posto, compreendemos que as respostas quando em relação a questões mais diretas a respeito do ensino por meio da diversidade, foram sempre afirmativas, e, sem tal direcionamento, retirar foram negativas, isto é, os professores não mencionam a importância da diversidade da língua no ensino de língua materna, o que, mais uma vez, evidencia suas crenças relacionadas ao ensino da língua.

\section{Considerações finais}

O presente trabalho abordou as crenças e as atitudes linguísticas dos professores da rede pública de ensino, especificamente, quanto ao julgamento da abordagem da variação linguística em sala. O percurso da pesquisa evidenciou que ainda há um longo caminho a percorrer, no que tange ao ensino de língua portuguesa contemplando suas variedades linguísticas. A trajetória trouxe inúmeras indagações a respeito da formação docente.

O grupo de professores analisado afirmou desconhecer ou conhecer de forma resumida os estudos da sociolinguística, o que comprova suas crenças, quando apresentam respostas que evidenciam apenas o padrão normativo. Observamos que esses professores estão há muito tempo sem realizar cursos de 
formação continuada, o que colabora para que desconheçam os estudos mais recentes voltados para o eniso da língua materna por meio da diversidade linguística, isto é, ainda utilizam metodogias e teorias anteriores que tinham por intuito o ensino descontextualizado.

\section{Referências bibliográficas}

ALKIMIN, Tânia Maria. Sociolinguística. In: MUSSALIM, Fernanda; BENTES, Anna Christina (Orgs.). Introdução a linguística: domínios e fronteiras. São Paulo: Cortez, 2003. p. 21-47.

BORTONI-RICARDO, Stella Maris. O português brasileiro. In: Educação em língua materna: a sociolinguística na sala de aula. São Paulo, Parábola Editorial, 2004.

BRASIL, Secretaria de Educação Fundamental. Parâmetros curriculares nacionais: terceiro e quatro ciclos do ensino fundamental: Língua Portuguesa. Brasília: MEC/SEF, 1998.

FARACO, Carlos Alberto. Norma culta brasileira: desatando alguns nós. São Paulo, Parábola Editora, 2008.

GALEMBECK, Paulo de Tarso. Preservação da face e manifestações de opiniões: caso de jogo duplo. In. PRETI, Dino (Org.). O discurso oral culto. $3^{a}$ ed. São Paulo: Humanitas, 2005. p. 173-194.

LAMBERT, W. W; LAMBERT, W. E. Psicologia social. Rio de Janeiro: Zahar, 1966. MORALES, Humberto López. Sociolinguística. $2^{\mathrm{a} e d . ~ M a d r i d: ~ E d i t o r i a l ~ G r e d o s, ~}$ 1993.

SILVA, Rosa Virgínia Mattos. O português são dois: novas fronteiras, velhos problemas. São Paulo: Parábola Editorial, 2004. 